\title{
Energy audit as an input for energy management and energy efficiency improvement in a gypsum manufacturing plant
}

\author{
H. Bernardo ${ }^{1,2}$, F. Oliveira ${ }^{1,2}$ and L. Serrano ${ }^{2,3}$ \\ ${ }^{1}$ INESC Coimbra - Institute for Systems Engineering and Computers at Coimbra \\ Rua Antero de Quental, 199, 3000-033 Coimbra, Portugal \\ Phone: +351 239851 040, e-mail: hbernardo@inescc.pt \\ ${ }^{2}$ School of Technology and Management, Polytechnic Institute of Leiria \\ Campus 2, Alto do Vieiro, 2411-901 Leiria, Apartado 4163, Portugal
}

Phone: +351 244820 300, e-mails: hermano.bernardo@ipleiria.pt, ftadeu@ipleiria.pt, luis.serrano@ipleiria.pt

${ }^{3}$ ADAI - Association for the Development of Industrial Aerodynamics, LAETA

Rua Pedro Hispano, $n^{\circ} 12$, 3030-601 Coimbra, Portugal

Phone: +351239708580

\begin{abstract}
This paper aims at presenting the main results of an energy audit performed to a gypsum production plant, in Portugal, which due to the amount of energy consumed must comply with the Portuguese program SGCIE (Intensive Energy Consumption Management System). The program was created in 2008 to promote energy efficiency and energy consumption monitoring in intensive energy consuming facilities (energy consumption higher than 500 toe per year). Facilities operators are required to perform energy audits and take actions to draw up an action plan for energy efficiency, establishing targets for energy consumption reduction and greenhouse gases emissions indexes. An energy audit was carried out to identify potential energy conservation measures for improving energy efficiency, and also typical energy consumption patterns, sector/equipment load profiles and thermal equipment performance. This tool gives managers the information to support decision making on improving energy performance and reducing greenhouse gas emissions. A number of tangible targets and measures were devised and set to be implemented in the next few years. Results show that there is a considerable potential for reduction in the energy consumption and greenhouse gases emissions of gypsum manufacturing plants. Here, as elsewhere in the industrial sector, energy efficiency can only be achieved through a continuous energy monitoring and management system.
\end{abstract}

\section{Key words}

Energy audit, energy efficiency, energy conservation measures, gypsum manufacturing.

\section{Introduction}

Gypsum is a calcium sulphate dihydrate, a white or grey naturally occurring mineral. Raw gypsum ore is processed into a variety of products such as a Portland cement additive, soil conditioner, industrial and building plasters, and gypsum wallboard [1]. Gypsum related products currently have a widespread application from building rehabilitation to new building construction [2].

Rising population and increasing wealth are fuelling growing global demand for products, services, buildings, and public infrastructure [3]. The industrial sector, which manufactures these products and structures, has many opportunities to improve its energy efficiency and to reduce its greenhouse gases (GHG) emissions.

An important characteristic of gypsum is that it can be perpetually recyclable and only a small quantity is currently recycled from building demolition waste due to challenges concerning contamination with other materials [4]. This leads to continuing research and development in this field, in order to increase the reductions of GHG emissions to produce new material and also avoid the over exploration of raw materials reducing the pressure on natural resources.

In order to be used, raw gypsum has to undergo a calcination process. There is a large amount of equipment required to operate in the gypsum calcination process, which results in a significant overall energy consumption financial costs and greenhouse gas emissions (GHG), with the corresponding consequences to the environment. Good energy management practices result in facilities with better energy and environmental performance. In order to implement actions that improve energy efficiency, it is necessary for the plant operation to be associated with an effective energy management methodology, as well as efficient facilities management procedures. One of the ways to achieve this is through the monitoring and targeting of energy consumption, which mainly consists of using management techniques to control energy consumption and cost. 
The ISO standard 50001:2011 intends to provide organizations with a recognized framework for integrating energy performance into their management practices, setting requirements for the implementation of energy management systems (EnMS), based on the Plan-Do-Check-Act (PDCA) continual improvement methodology [5].

According to the proposed framework, organizations shall continuously seek ways to improve their energy usage, thus perpetually reducing the operating costs. When organizations start observing the financial returns from energy management they shall continuously strive to improve their energy performance. The key issue is regular assessment of energy performance and implementation of actions to increase energy efficiency.

Moreover, the implementation of any energy management system should be preceded by an energy audit [6], which consists of a detailed examination of the energy usage conditions in an installation - a vital tool that gives managers the information to support decision making on improving energy performance [7]. Energy audits are not only essential for improving energy efficiency and performance, but also represent a key step in the process of reducing GHG emissions from buildings, facilities, industrial processes and transport systems.

\section{Methodological approach}

The work performed during the energy audit required a coordinated, phased approach to identify, evaluate and recommend energy conservation measures (ECM). The energy audit started with collecting and gathering preliminary data on the plant facilities; afterwards, a plant inspection and the installation of energy monitoring equipment took place, in order evaluate the performance of some equipment and to identify potential ECMs; finally, an energy audit report was written, integrating an action plan for energy consumption reduction, establishing targets for energy consumption reduction and GHG emissions indexes.

Fig. 2 illustrates a schematic representation of the different stages of the energy audit performed to the gypsum manufacturing plant.

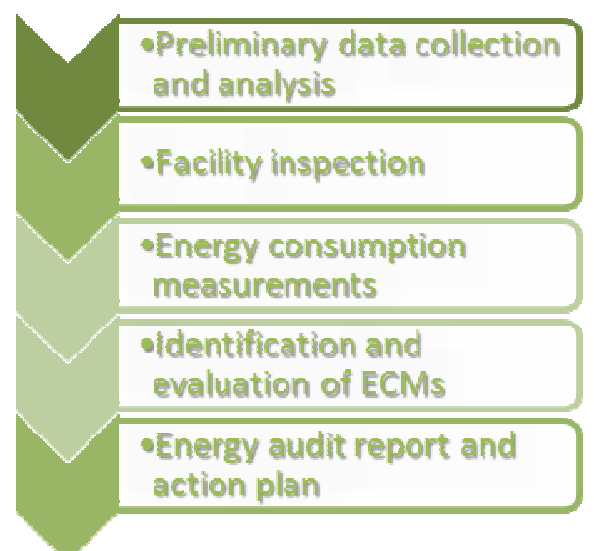

Fig. 2. Energy audit phases.
The preliminary data collection and analysis consisted in a review of the facility energy bills and monthly production data, along with other current and historic energy and production related data. The architectural and engineering plans of the plant and its systems in conjunction with data inventory of the different energy related systems (mill, fan, compressed air, calcination kilns, etc.) were assessed in detail to identify the major energy consumers in the plant. At this stage, general information about the facility (year of construction, upgrades, types of products, operation schedule, operating hours, scheduled shutdowns, etc.) was also collected.

This information was useful for the planning of the plant inspections, identifying the main issues to be discussed and analysed during the on-site visits.

After the preliminary analysis, a facility inspection was performed, which consisted of a number of on-site visits to inspect the actual systems and obtain answers to the questions from the preliminary review. The audit team also met with the operation and maintenance staff to obtain an introduction and to establish a common understanding of the audit process. At this stage it is important to get a deeper insight on the processes and utilities of the facility, so comments from the facility workers were also taken into consideration and some readily-available data was collected. The electrical load and thermal energy use inventory was completed with the identification of major energy consumption systems and equipment. Some data were available and collected from the staff of the plant being audited, while other data was collected through measurement and recording. During these visits the existing measurement instrumentation and the type of recorded data was also verified, in order to identify what additional measurements would be required.

The on-site energy consumption measurements were performed on specific equipment and systems to evaluate its load profile and identify potential ECMs. Other physical variables were also measured in order to assess the performance of thermal process equipment. Gathering data through measurement is one of the main activities of energy auditing, because without adequate and accurate data, an energy audit cannot be successfully accomplished. This stage was very important to establish the quantification of energy flows and assess the energy performance of the facility.

The information gathered during the facility inspection and the energy consumption measurements was then reviewed and organized. Along with this, a set of opportunities to improve the energy efficiency were studied to estimate the energy savings potential and the implementation cost. Measures with a lack of potential or without cost effectiveness were disregarded. The simple payback method was used to assess the cost effectiveness of each ECM.

The energy audit report was prepared taking in consideration the interest of the stakeholders in each section. Therefore, there was an effort to customize each section in order to give a rich picture of the work 
developed and the proposed ECMs to improve the performance and reduce the energy bills of the facility. The report includes an action plan for the implementation of each ECM, with a clear description of goals, saving targets, and the definition of roles and responsibilities for its execution.

The conversion factors to primary energy used were the following, according to Portuguese norm (Despacho n. $\left.{ }^{\circ} 17313 / 2008\right)$ : 0,000215 toe/kWh for electricity, 1,077 toe/ton for natural gas and 1,01 toe/ton for diesel, parameters defined due to the energy mix of the country. To compute the GHG emissions, the factors used were the following, also according to the previously referred Portuguese norm: $0,47 \mathrm{kgCO}_{2} / \mathrm{kWh}$ for electrical energy, $2683,7 \mathrm{kgCO}_{2} /$ toe for natural gas and $3098,2 \mathrm{kgCO}_{2} /$ toe for diesel.

\section{Description of the production process}

The energy audit was performed to a gypsum manufacturing plant, located in Portugal. Fig. 3 shows the simplified flow diagram of the production process.

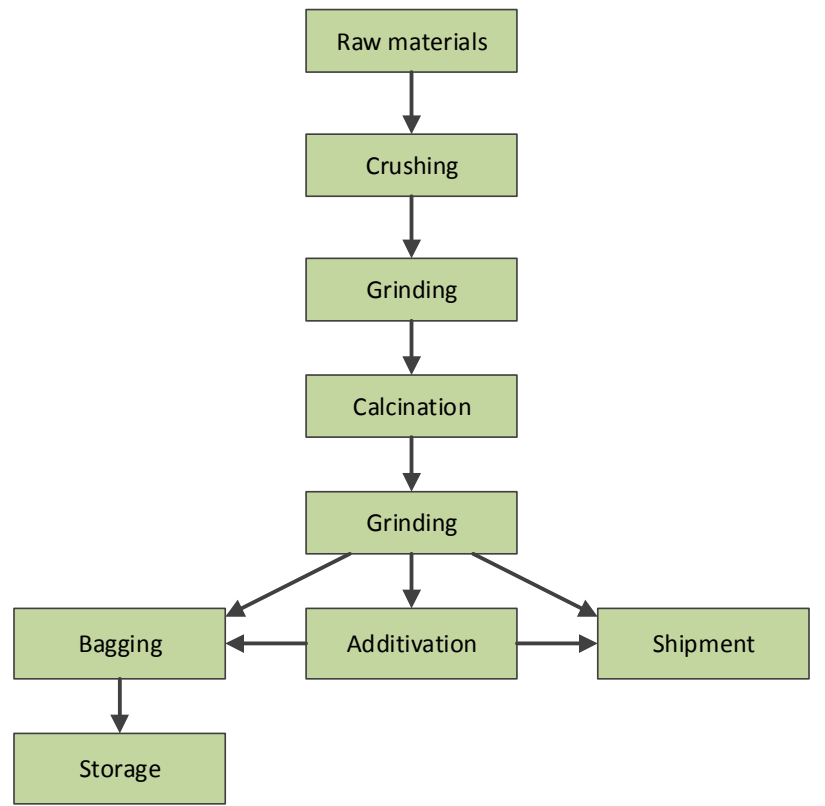

Fig. 3. Gypsum production process.

Trucks unload raw materials in the reception area where it is stockpiled in an outdoor park and in shelters. The materials are loaded into an impact crushing mill designed to break larger rocks into small pieces. Then, materials are reduced to powder in hammer grinding mills.

Subsequently, the powder is heated in calcination kilns to remove about three quarters of the chemically bound water, at 120 to $150^{\circ} \mathrm{C}$, approximately. Calcination is performed in three different kilns, operating either in batch or in continuous mode.

The material is then grounded and stored in large silos for further grinding in roller mills until the required particle size is obtained.
The grounded and grinded material may be mixed with additives to obtain specific products or simply shipped as it is in bulk or in bags.

There are storage bins and silos located downstream of the mills and of the calcination process for intermediate storage.

\section{Energy consumption analysis}

The first step of the energy audit performed consisted in the compilation and quantification of the facilities current and historical energy usage and associated utility costs in order to establish the energy consumption baseline. For this study, baseline energy use was established from the monthly utility bills of 2013. On Fig. 4 the energy consumption, in terms of final energy and primary energy, and GHG emissions for the baseline year are shown. Due to confidentiality restrictions, only percentages are presented.

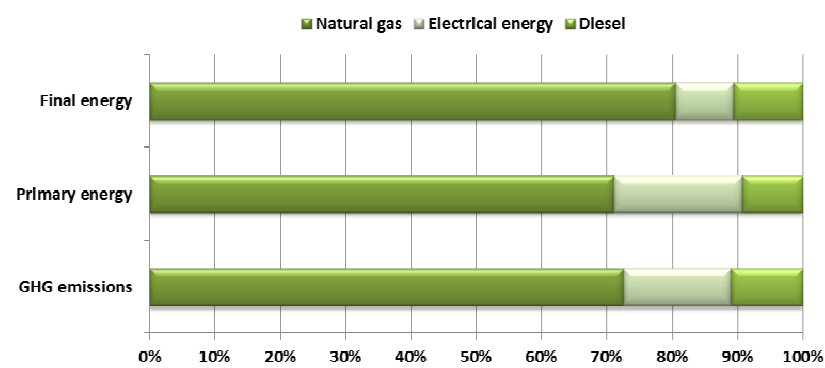

Fig. 4. Baseline energy consumption and GHG emissions.

It is important to establish the existing patterns of energy usage, disaggregating the energy consumption by each sector or end-use. This will help to identify the sectors where the energy consumption reduction could be more significant. Fig. 5 shows the estimated breakdown of primary energy consumption by end-use equipment, per year, based on the measured data.

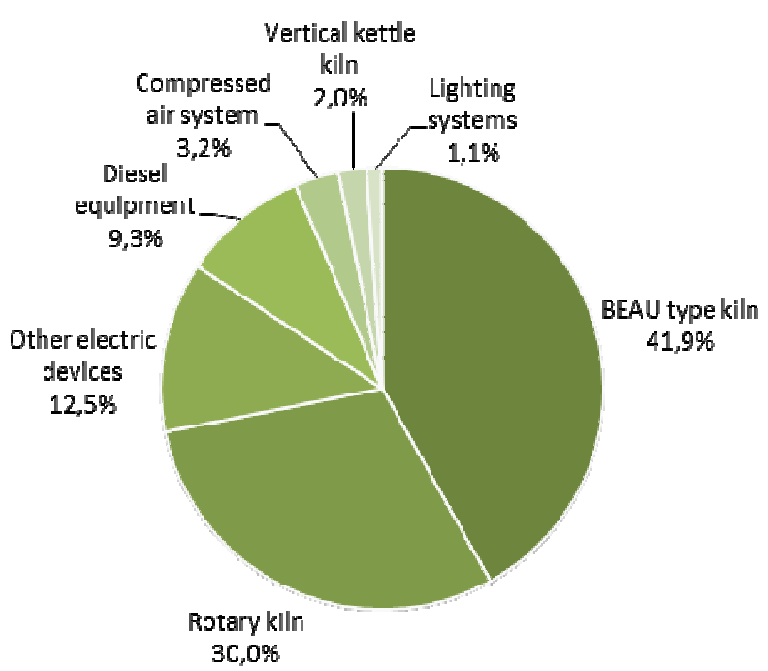

Fig. 5. Breakdown of primary energy consumption by sector/end-use. 
The calcination process is performed by natural gas fuelled kilns and consumes more than $50 \%$ of the total amount of energy, being a crucial sector for increasing the energy efficiency of the facility.

The BEAU type kiln, which is the major energy consumer $(41,9 \%)$, is a batch mode calcination kiln. The rotary kiln rotates slowly to move the material towards the direction of the flame to the lower end of the kiln, in a continuous mode operation. This is responsible for $30 \%$ of the total amount of consumed energy. There is also an old vertical kettle kiln that is responsible for $2 \%$ of the total amount of energy consumed.

There is a considerable amount of other, smaller electric equipment, mainly used to transfer materials from one stage of the process to another by means of screw conveyors or bucket elevators, including also the crushing and grinding mills.

Diesel equipment consists mostly in trucks for transportation and distribution of the processed products to the costumers, but there are also some forklifts and a loader in the facility.

In order to define targets to reduce energy consumptions it is necessary to establish a metric to compare the energy efficiency of the facility and report potential improvements, over the years. In the present study the index used is based on the ratio between energy consumption and production, which is measured in tons of gypsum produced per year. Assuming production to be constant throughout the next few years, reducing this index is equivalent to reducing energy consumption.

\section{Energy conservation measures}

During the energy audit several ECM were identified and its savings potential was estimated. The energy consumption in the year 2013 was considered as the baseline to study the savings potential of energy and cost, and the payback time was used as economic criteria to determine the cost effectiveness of each measure, due to its simplicity. The different ECMs analysed and proposed for the facility are described in the following subsections.

\section{A. Enhancement of compressed air system performance}

The compressed air system is a significant electrical energy consumer, with a large improvement potential. A package of three integrated interventions are proposed, in order to improve the overall performance of the system: a) mending existing leaks and implementing leak detection procedures to detect and repair new air leaks sooner; b) reducing the operating pressure of system, which is made possible by the previous measure, leading to a decrease in the energy demand without the risk of occurring an excessive pressure drop; and c) elimination of $80 \%$ of the empty load periods of the compressor. The estimated total annual savings due the enhancement of the compressed air systems is 8,8 toe.

\section{B. Improvement of lighting systems}

The improvement of lighting systems consists in the refurbishing of the existing indoor fluorescent lighting system, replacing existing T8fluorescent lamps with T5 fluorescent lamps. This ECM leads to an estimated overall annual reduction of 3,6 toe.

\section{Replacement of standard-efficiency motors and installation of VSDs}

In order to reduce the energy consumption due to electric motors, six electric motors are planned to be replaced with higher efficiency equivalents, or lower power motors in the cases where the existing motors are over-dimensioned. These motors are associated with crushing and grinding mills. Also, variable speed drives (VSD) are to be installed to drive the motors of the mills. The annual amount of energy savings in the motor systems is expected to be 13,7 toe.

\section{Elimination of residual water in raw material and efficiency improvement of calcination kilns}

The raw materials are stored outside of the plant, in a place only partially sheltered, and they are frequently wet or damp, according to weather conditions. An expansion of the sheltered area is proposed, in order to reduce the exposure of raw materials to rain and, consequently, the energy needs for drying it. Also recommended is the installation of a drying equipment to dry the raw material, using the energy available in the exhaust gases, before the calcination kilns. Along with this, it is proposed to apply thermal insulation in some components of BEAU type kiln and to regulate the combustion parameters of the rotary kiln and of the vertical kettle kiln. This is expected to result in an energy consumption reduction of 75,1 toe per year.

\section{E. Summary of energy and cost savings}

The feasibility of each ECM was measured through a simple payback analysis. Table I summarizes the potential energy and cost savings, investment and payback time computed, for each of the previously presented ECMs. The unit cost of energy was determined from the monthly utility bills.

Table I. Summary of potential energy and cost savings, investment and payback.

\begin{tabular}{|c|c|c|c|c|c|}
\hline ECM & $\begin{array}{c}\text { Energy } \\
\text { savings } \\
{[\text { toe] }}\end{array}$ & $\begin{array}{c}\text { GHG } \\
\text { savings } \\
{[\text { tCO2e] }}\end{array}$ & $\begin{array}{c}\text { Cost } \\
\text { savings } \\
{[€]}\end{array}$ & $\begin{array}{c}\text { Investment } \\
{[€]}\end{array}$ & $\begin{array}{c}\text { Payback } \\
\text { [years] }\end{array}$ \\
\hline A & 8,8 & 19,4 & 4051 & 2000 & 0,5 \\
\hline B & 3,6 & 7,9 & 1649 & 8991 & 5,4 \\
\hline C & 13,7 & 30,0 & 6062 & 29195 & 4,8 \\
\hline D & 75,1 & 201,4 & 33834 & 135500 & 4,0 \\
\hline Total & 101,2 & 258,8 & 45596 & 175686 & 3,8 \\
\hline
\end{tabular}


According to the values presented in Table I it is patent that the total amount of energy savings is 101,2 toe, corresponds to a reduction of around $8 \%$ in the annual energy consumption of the facility, thus allowing compliance with SGCIE. The total investment to implement the proposed ECMs is an estimated 175686 EUR, with an overall payback time of 3,8 years.

\section{Conclusions and outlook}

Some sectors and equipment with significant energy consumption were found to have a potential for improvement through the implementation of ECMs, and the energy audit was an effective tool to identify the potential volume and the priority of actions to be implemented. The proposed ECMs will allow energy consumption to be reduced by $8 \%$, resulting in a total cost saving of 45596 EUR per year.

Energy audits provide the information that energy managers need to identify energy consumption patterns, disaggregate energy consumption for the main components of a facility and document existing conditions. ECMs can be identified and prioritized according to its cost effectiveness.

By taking an open-minded and methodical approach to the audit process, it is possible to identify and avoid unnecessary spending in most facilities while improving the operation and production process.

While the results obtained and presented here are only valid for this particular facility, they can be used as a comparison term when addressing other similar facilities in layout and process, and the methods used here can be applied, with the adequate adjustments, to audits to different facilities.

\section{References}

[1] EPA, "AP 42: Compilation of Air Pollutant Emission Factors," 1995.

[2] EuroGypsum, "Building Value for Society Sustainability of Gypsum : our Assets.” EuroGypsum, Brussels.

[3] D. Gielen, J. Newman, and M. K. Patel, "Reducing Industrial Energy Use and CO 2 Emissions: The Role of Materials Science," MRS Bull., vol. 33, no. April, pp. 471-478, 2008.

[4] EuroGypsum, "What is Gypsum?" EuroGypsum, Brussels, 2007.

[5] ISO, "ISO 50001: 2011. Energy management systems - Requirements with guidance for use," 2011.

[6] W. Turner and S. Doty, Energy Management Handbook: Sixth edition. The Fairmont Press, Inc., 2004, p. 850.

[7] A. Thumann and W. Younger, Handbook of Energy Audits: Sixth edition. The Fairmont Press, Inc, 2003, p. 440. 